\title{
Influence of nitrogen fertilization on sugarbeet (Beta vulgaris) quality in an area of southern Spain
}

\author{
A. TRONCOSO and M. CANTOS \\ Instituto de Recursos Naturales y Agrobiología de Sevilla, C.S.I.C., B.P.O. 1052, E-41080 Sevilla, \\ Spain
}

Key words: Beta vulgaris L., nitrogen, sucrose quality, sugarbeet

\begin{abstract}
Influence of soil nitrogen availability on quality components (sucrose, alpha-amino nitrogen, $\mathrm{K}^{+}$and $\mathrm{Na}^{+}$) of sugarbeet was studied. This study was carried out on a homogeneous soil of southern Spain. We have tested $0,100,150,200$ and $250 \mathrm{~kg} \mathrm{~N} / \mathrm{ha}$. The use of increasing quantities of nitrogen fertilizer leads to a large decrease in sucrose concentration in the root, but also to a large increase in root production. This inverse relation does not exist at high levels of fertilization. Sugar yield per ha is most increased between 100 and $150 \mathrm{~kg} \mathrm{~N} / \mathrm{ha}$. On the other hand, the increase of nitrogen fertilization leads to a significant increase of alpha-amino nitrogen. High levels of nitrogen fertilization have a decisive negative effect on the juice purity calculated according to the Wieninger and Kubadinov equation, and therefore on the recovery of sucrose from the root tissue.
\end{abstract}

\section{Introduction}

The nitrogen ratio released every year from organic matter is not sufficient to cover the metabolic needs of sugarbeet for an adequate production. For this reason, addition of this element as fertilizer is necessary. However, an excessive increase in nitrogen application results in enhanced levels of $\alpha-\mathrm{NH}_{2}-\mathrm{N}$ in the root (Vielemeyer, 1986). This nitrogen form makes the subsequent sucrose extraction difficult. Thus, a better nitrogen nutrition for optimal sucrose recovery is necessary.

A number of experiments were carried out to study the effect of different fertilization levels on root yield and sucrose production of sugarbeet, and on the parameters used to estimate beet root quality, according to Wieninger and Kubadinov (1971).

\section{Materials and methods}

The nitrogen fertilization was carried out in the
Torre de la Marisma farm in Sevilla (Spain) during three growing seasons. A site with a very homogeneous soil (Pelloxererts) of $25500 \mathrm{~m}^{2}$ surface was chosen, divided in seven equal blocks $\left(3600 \mathrm{~m}^{2}\right.$ each $)$. We have tested nitrogen application rates of $0,100,150,200$ and $250 \mathrm{~kg} \mathrm{~N} / \mathrm{ha}$, with occasional irrigation.

A Venema autoanalyzer was used to analyze the sugarbeet roots (British Sugar Company method).

\section{Results and discussion}

There is an inverse relation between nitrogen fertilization and root sucrose content $(\mathrm{r}=$ $-0.920 ; P \leqslant 0.01$; Fig. 1).

On the contrary, increase of nitrogen fertilization results in higher yields, expressed as weight of roots per ha $(\mathrm{r}=0.787 ; P \leqslant 0.05$; Fig. 2$)$. However, this positive relation disappears with higher levels of fertilization and, consequently, an excess of nitrogen fertilizers was not profitable from this point of view. 
When the nitrogen supply was compared with the sucrose yield ( $\mathrm{kg}$ per ha), a clear relation was not found $(\mathrm{r}=0.439$; Fig. 3). In any case, the sugar yield per ha is increased between 100 and $150 \mathrm{~kg} \mathrm{~N} / \mathrm{ha}$, being lower in the control and also especially when the quantity of nitrogen is excessive although with poor statistical significance.

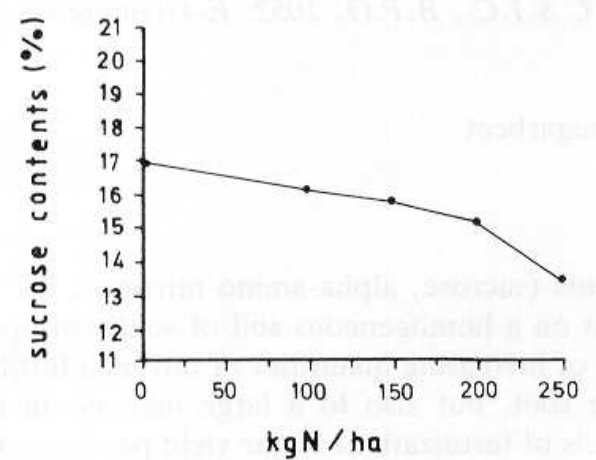

Fig. 1. Relation between nitrogen fertilization and sucrose in root.

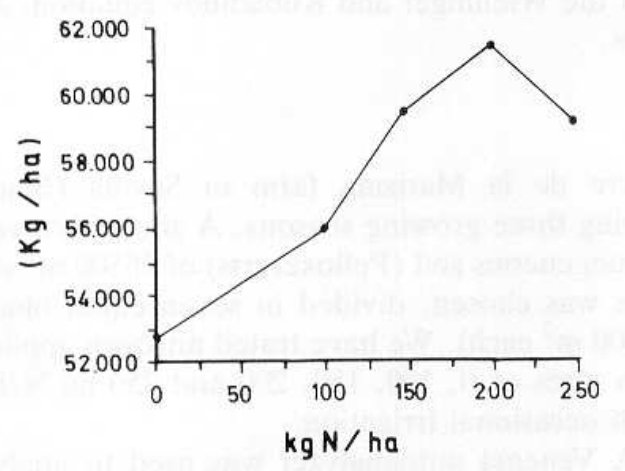

Fig. 2. Relation between nitrogen fertilization and production of roots.

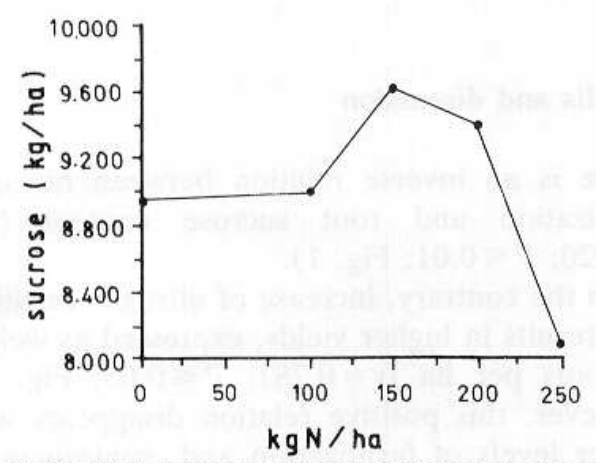

Fig. 3. Relation between nitrogen fertilization and sucrose production.
In Figure 4, it was observed that very high levels of nitrogen application, higher than 200 $\mathrm{kg} / \mathrm{ha}$, lead to a significant increase of alphaamino nitrogen $(\mathrm{r}=0.908 ; P<0.05)$; therefore there is a decrease of juice purity as nitrogen fertilizer application is increased (Fig. 5).

The recoverable sucrose was calculated from

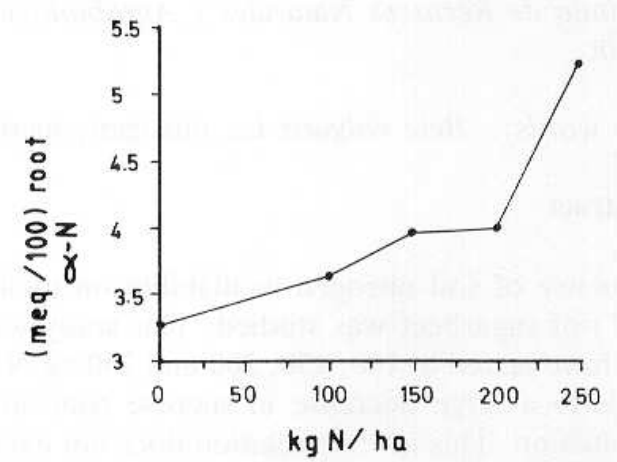

Fig. 4. Relation between nitrogen fertilization and $\alpha \mathrm{N}$ concentration in root.

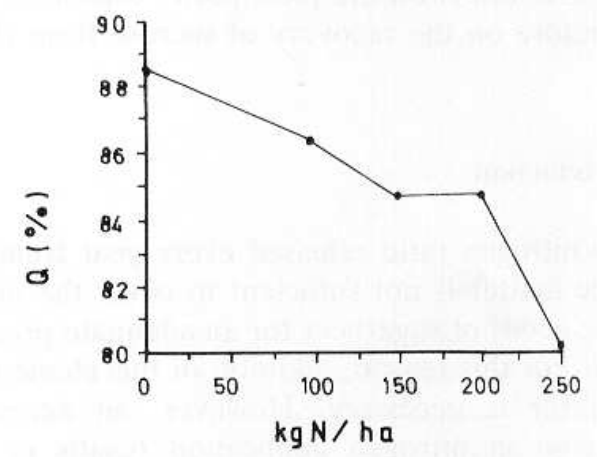

Fig. 5. Relation between nitrogen fertilization and juice purity.

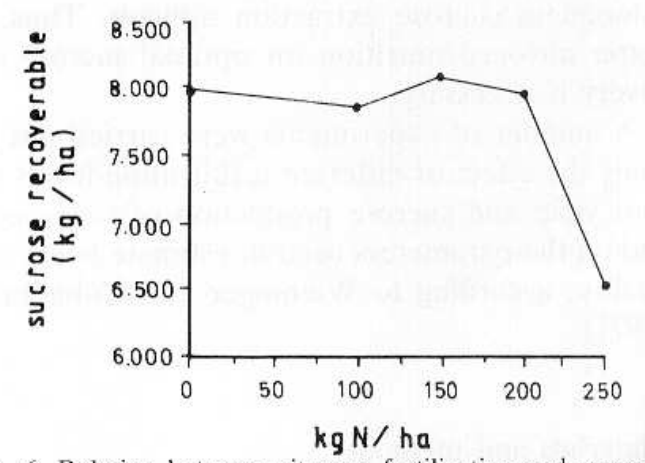

Fig. 6. Relation between nitrogen fertilization and recover able sucrose. 
the juice purity and the sucrose yield per ha (Fig. 6). Doses above $150 \mathrm{~kg} \mathrm{~N} / \mathrm{ha}$ lead to a decisive decrease of the sucrose recovery.

These nitrogen fertilization experiments demonstrate the negative effects of nitrogen fertilization levels above $200 \mathrm{~kg} \mathrm{~N} /$ ha on the sugar production of sugarbeet in this area of Spain, since these levels induce decreases in the root yield per ha, juice purity and recoverable sucrose.

\section{References}

Vielemeyer H P 1986 Influence de l'époque d'apport de N sur le processus de formation du rendement dans la betterave sucrière. Arch. Acker-Pflanzenbau Bodenk. 30, 131-137.

Wieninger L and Kubadinow N 1971 Beziehungen zwischen Rübenanalysen und technischer Bewertung von Zuckerrüben. Comunication presenteé a la 14émé Assemblée Generale de la CITS. 